\title{
From Carbenes to Peroxidic Antimalarial Drugs. Highlights from the Scientific Work of Charles William Jefford
}

\author{
Ulrich Burger*
}

\begin{abstract}
A concise biography of C.W. Jefford, Professor of Chemistry in Geneva from 1969 to 1994, is given. A personal tribute by the author is paid to Jefford's fundamental work in the field of singlet oxygen, endo-peroxides, and 1,2,4-trioxanes as remedies against malaria.
\end{abstract}

Keywords: Artemisinin mimics · History · Jefford, C. W. · Malaria · 1,2,4-Trioxanes

This issue of CHIMIA dealing with chemistry at the University of Geneva would be incomplete without reference to C.W. Jefford and his achievements. Born in 1929 in Farnborough (UK), he graduated from Oxford University, subsequently obtaining his $\mathrm{PhD}$ at Princeton University $(\mathrm{NJ})$ with Edward C. Taylor. Jefford had already gained considerable experience as a Professor at Temple University, Philadelphia (PA), and as a Visiting Professor in Marseille and Strasbourg, when he was appointed in 1969 as Full Professor at the Faculty of Sciences in Geneva. Thus at age 40 , right after the student unrest and contestation that had shaken the old structures of the Schola Genevensis, he was appointed to build a modern department of organic chemistry in the then brand-new Sciences II building on the river Arve. Together with other faculty members, including the late Wolfgang v. Oppolzer, who joined the department in later years, he carried out this challenging job with great talent. Charles W. Jefford was an excellent, though demanding, teacher who launched generations of young chemists and biochemists

${ }^{\star}$ Correspondence: Dr. U. Burger Professor Emeritus

Department of Organic Chemistry

University of Geneva

$\mathrm{CH}-1211$ Geneva

Tel.: +41227510317

E-mail: Ulrich.burger@unige.ch

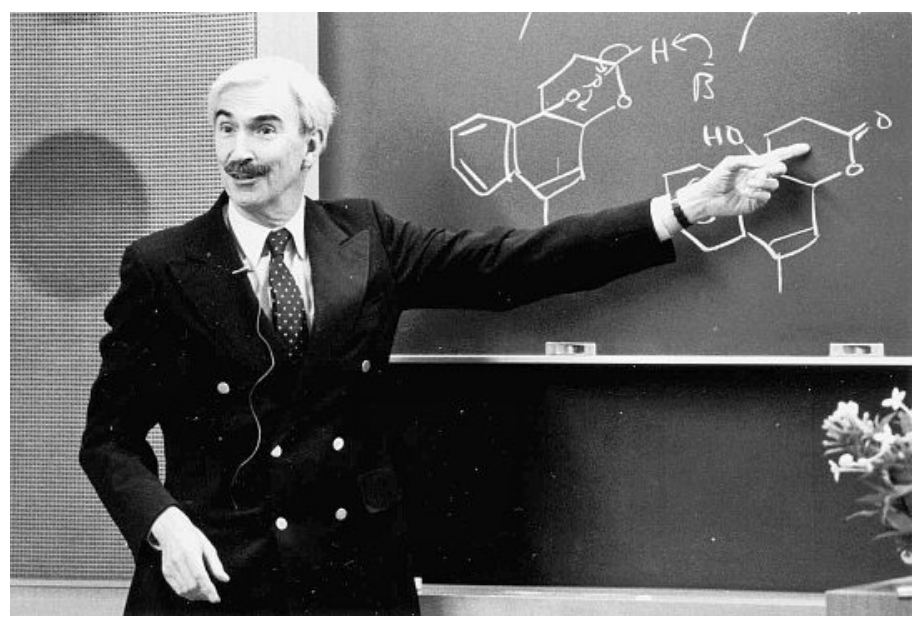

Fig. 1. Charles W. Jefford in 1984 at a conference in Osaka.

on their careers. He was also a brilliant speaker. The photograph taken in 1984 shows him in full flow at the blackboard during a lecture given in Osaka, Japan (Fig. 1). In 1994 he retired, leaving a prestigious and internationally renowned department to his successors.

During the late sixties and early seventies, mechanistic organic chemistry and semi-empirical computational methods were at their height. The advent of the rules of conservation of molecular orbital symmetry had revolutionised the understanding of pericyclic reactions. ${ }^{[1]}$ Most of Jefford's early and prolific research work dealing with halocarbene additions to strained bicycloalkenes and their use in the synthesis of small cage type compounds has to be seen in this context. [2] Bicyclo[2.2.2] octa-2,5,7-triene (barrelene), benzobarrelene, and many other fashionable cage compounds were prepared which were of interest to physical chemistry due to their bond tautomerism or peculiar $\pi$-systems. ${ }^{[3]}$ Undoubtedly an important result of Jefford's carbene and cage years was the finding that difluorocarbene adds to norbornadiene (1) to give the quadricyclic compound 2, accompanied by the expected products of the classic cyclopropanation, 3 and 4. This reaction constituted an unprecedented case of a linear cheletropic carbene reaction (Scheme 1). ${ }^{[4]}$

From the late seventies on, Jefford's interest shifted more and more towards the chemistry of singlet oxygen $\left({ }^{1} \mathrm{O}_{2}\right)$. In a noteworthy study the hitherto enigmatic sensitised photooxygenation of adamantylideneadamantane (5) was reexamined and elucidated. ${ }^{[5]}$ This doublecage alkene gives with sensitizers such as methylene blue (MB) or meso-tetraphenylporphine (m-TPP) almost exclusively the expected dioxetane (6). However, when rose bengal (RB) was used as sensitizer, the epoxide (7) became the main product (Scheme 2). The key to understanding this puzzling change in behaviour was found to be a single electron transfer (SET) occurring between $\mathrm{RB}$ and the initially formed ${ }^{1} \mathrm{O}_{2}$. The ensuing superoxide radical $\left(\mathrm{O}_{2}\right)$ then triggers a chain reaction that, with 


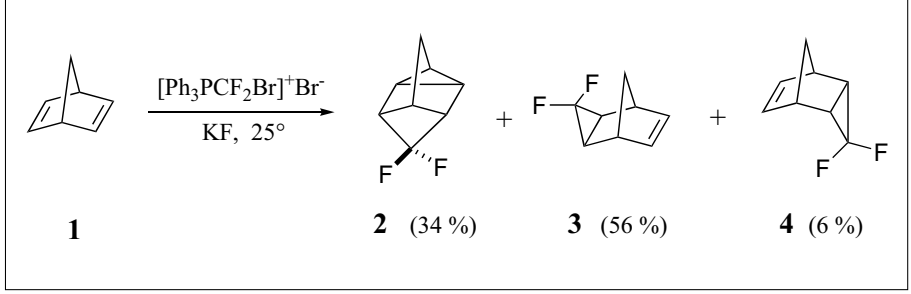

Scheme 1. The first genuine case of a linear cheletropic carbene reaction $(1 \rightarrow 2)$.

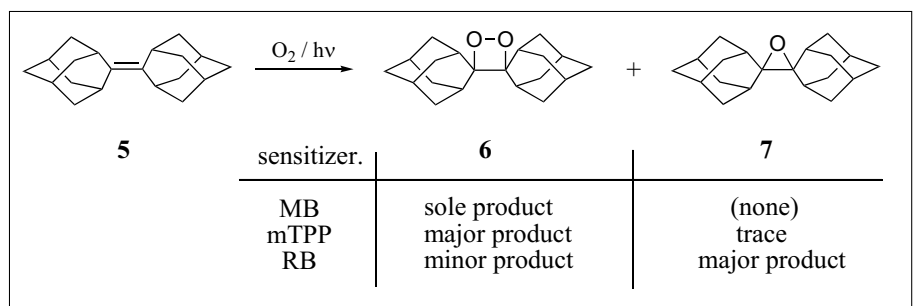

Scheme 2. The abnormal epoxidation (MB = methylene blue; $\mathrm{mTPP}=$ meso tetraphenylporphine; $\mathrm{RB}=$ rose bengal).

traces of moisture, gives $\mathrm{H}_{2} \mathrm{O}_{2}$, the ultimate epoxidising agent (Scheme 2). The implication of the superoxide radical was later confirmed by a solid-state EPR experiment. ${ }^{[5 c]}$

By his careful work on the photooxygenation of enol ethers and enamines, Jefford discovered the importance of zwitterionic peroxides as reactive intermediates. This led eventually to the finding that aldehydes can be incorporated into the photooxygenation process to give 1,2,4-trioxanes. ${ }^{[6]}$ An illustration, outlined in Scheme 3 , is the behaviour of 2-(methoxymethylene)adamantane (8). This enol ether undergoes in aprotic solvents dye-sensitized photooxidation to give the dioxetane $\mathbf{9}$, or after work-up, adamantanone (10). However, when $\mathbf{8}$ was photooxidized in a solution of acetaldehyde at $-78{ }^{\circ} \mathrm{C}$ with rose bengal (RB) as sensitizer, the diastereomeric trioxanes (11) were formed in over $50 \%$ total yield together with $\mathbf{9}$. Clearly an intermediate, namely the zwitterionic peroxide $\mathbf{1 2}$ is involved and captured by the aldehyde. Note that the abnormal epoxidation mentioned in the precedent paragraph, is not observed for this electron-rich olefin.

Another family of reactive intermediates closely related in their behaviour to the aforementioned zwitterionic peroxides is accessible by Lewis acid catalysed opening of certain 1,2-dioxetanes and endo-peroxides. ${ }^{[7]}$ This enabled Jefford to expand his original mechanistic finding into a general synthetic method for the preparation of a wide variety of tricyclic, bicyclic, and monocyclic 1,2,4-trioxanes. This class of compounds had not been readily accessible before. A typical synthesis is shown in Scheme 4. Reaction of the symmetric endo-peroxide, 1,4-diphe-

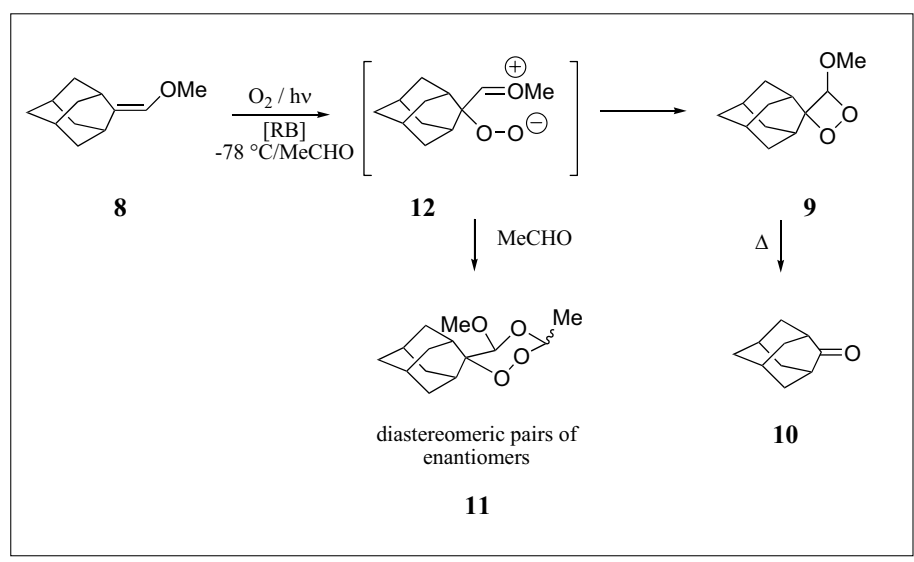

Scheme 3. Interception of a zwitterionic peroxide (12) by acetaldehyde.

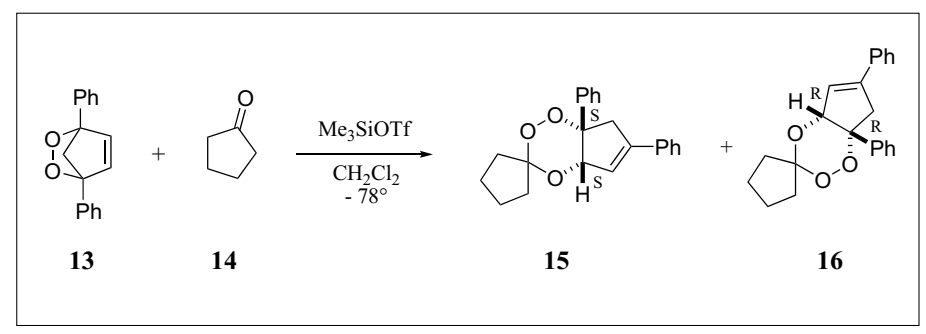

Scheme 4. Convenient synthesis of 1,2,4-trioxanes from endoperoxides.

nyl-2,3-dioxabicyclo[2.2.1]hept-5-ene (13) with cyclopentanone (14) in the presence of catalytic amounts of trimethylsilyl trifluormethanesulfonate $\left(\mathrm{Me}_{3} \mathrm{SiOTf}\right)$ in $\mathrm{CH}_{2} \mathrm{Cl}_{2}$ at $-78^{\circ} \mathrm{C}$ affords a racemic mixture of the cis-fused cyclopenta-1,2,4-trioxanes 15 and $\mathbf{1 6}$ in high yield as the sole products. In other words, the reaction course is highly diastereoselective. The mechanism has been clarified in great detail by investigation of the behaviour of chiral cyclic ketones e.g. (-)-menthone, (-)-carvone, and others. ${ }^{[7 \mathrm{~b}]}$

The importance of this achievement rests on its relation to the naturally occurring 1,2,4-trioxane artemisinin or qinghaosu (17). This sesquiterpene with potent antimalarial activity had been isolated in the early seventies in China from Artemisia annua L. Preparations made from this common shrub had been used since centuries in traditional Chinese medicine to reduce the malaria burden. This knowledge only reached the world outside China in the eighties. ${ }^{[8,9]}$ At that time conventional antimalarial remedies such as chloroquine and mefloquine had lost already much of their efficacy owing to the development of multidrug-resistant mutants of the Plasmodium parasite. Therefore, trioxane 17 and the 1,2-dioxane yingzhaosu (18), also found in China, became the most important leads for the development of antimalarial drugs. Jefford has written several reviews on this matter of global concern. ${ }^{[10]}$ His own synthetic work on 1,2,4-trioxanes came at the right time, providing access to synthetic mimics and, most importantly, it enabled the structure-activity profile to be studied, thereby revealing the process of action of peroxidic antimalarials.

The biological activity of a large variety of synthetic 1,2,4-trioxanes from Jefford's laboratory was systematically evaluated in vitro against chloroquine-sensitive and chloroquine-resistant Plasmodium falciparum parasites. ${ }^{[10,11]}$ Several of the new compounds were found to be nearly as active as the lead $\mathbf{1 7}$. This applies to $\mathbf{1 5}$ and 16 but also to the racemic tailor-made mimics 19 and 20. Other trioxanes, for instance, the fluorinated compound $\mathbf{2 1}$ and the spirocyclic ketone $\mathbf{2 2}$ were even more active than 17. However, some seemingly minor structural modifications brought about a sharp drop in activity. This applies to the semi-synthetic epiartemisinin (23) or to the tetramethyl compound $\mathbf{2 4}$ which is nearly inactive (Fig. 2).

In order to understand all this, one needs a good hypothesis for the mode of action of peroxidic antimalarial drugs. Although there is no full consensus today in the literature as to how artemisinin and its synthetic mimics kill the parasites, there is no doubt that the peroxidic bond is a necessary part of the pharmacophore. In Jefford's favoured model, the initial step that accounts for the Plasmodium specificity of the drugs is believed to be the docking of 


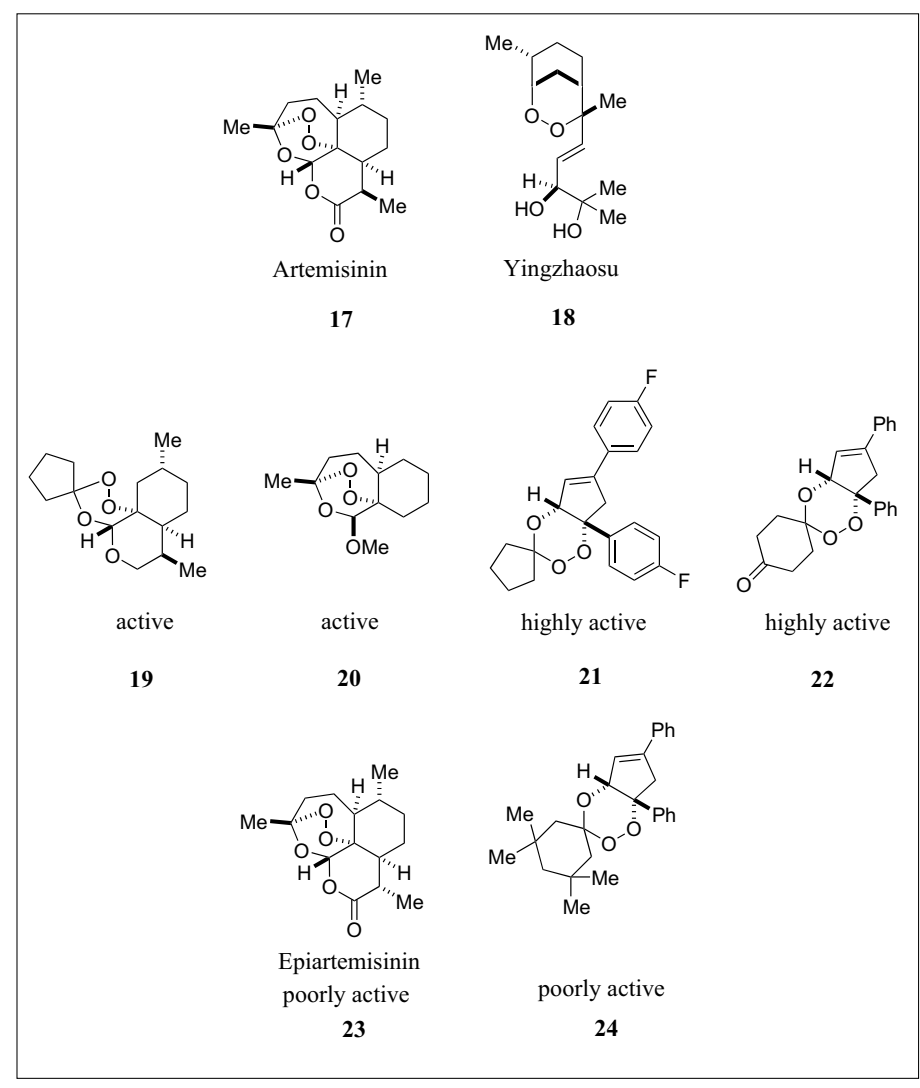

Fig. 2. Two peroxidic leads (17 and $\mathbf{1 8}$ ) and selected synthetic mimics of 17.

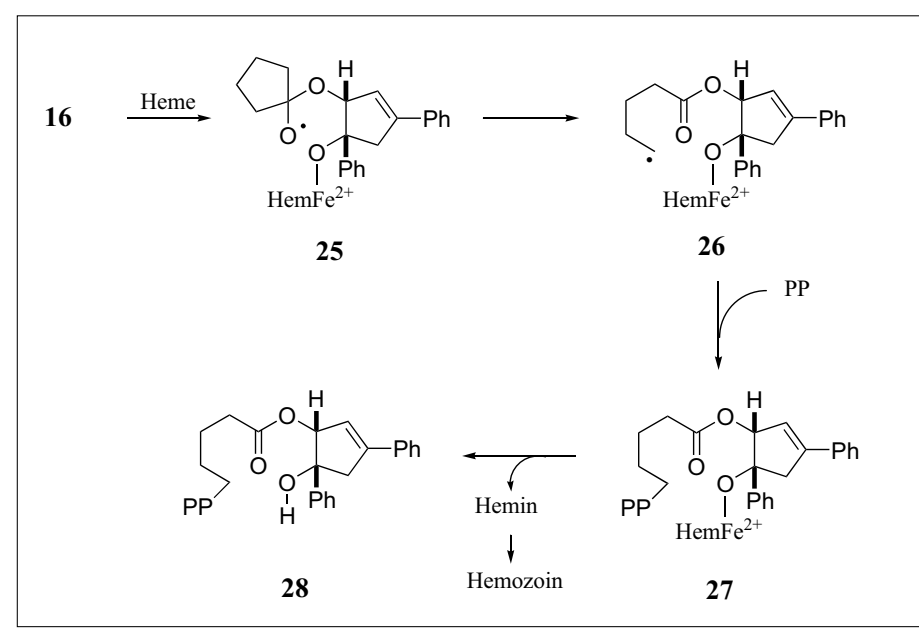

Scheme 5. Docking of $\mathbf{1 6}$ on heme produces the lethal carbon centered radical (26) which binds to parasitic protein (PP).

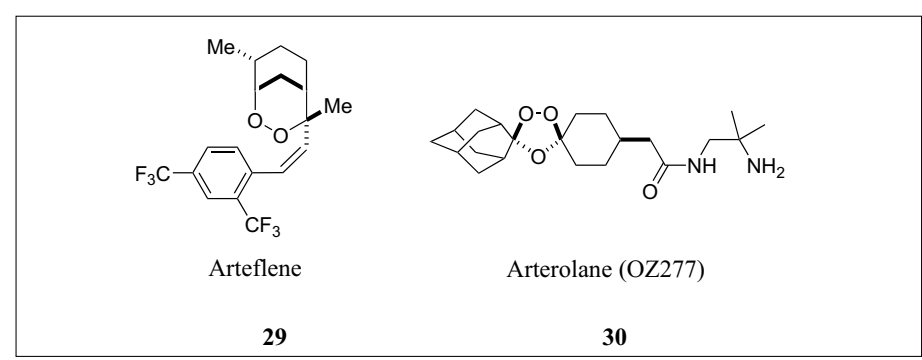

Fig. 3. Fall and rise of drug candidates. the 1,2,4-trioxane moiety on heme. In fact, after the host (human or rodent) is infected, Plasmodium parasites invade the erythrocytes, where they feed on hemoglobin to obtain amino acids for growth. The excised prosthetic group (heme) being toxic to the parasite, is normally, i.e. in absence of a drug, oxidised and polymerised to hemozoin, the dark-reddish malarial pigment. When the host is treated with an active peroxide, binding to heme triggers a cascade of chemical events. Taking trioxane $\mathbf{1 6}$ as an example (Scheme 5), the ferrous ion of heme attacks the peroxidic function breaking it apart to create a ferric oxide bond and an oxy radical 25 . The oxy radical then irreversibly rearranges to the thermodynamically stable ester function, simultaneously producing the carbon-centred radical $\mathbf{2 6}$, which is the lethal agent. It reacts with the protein of a nearby parasite, thereby causing its death. On protonation, 27 liberates the disabled alkylated parasite $\mathbf{2 8}$, hemin and, lastly, hemozoin.

Jefford provided very strong evidence in support of this working hypothesis, which became the guiding principle for subsequent work in his and many other laboratories. Thus, it was shown that both enantiomers of a synthetic drug had almost the same biological activity. This holds, for instance, for 15 vs. 16, or for the highly active fluorinated compounds (+)-21 vs. $(-)-21$. It was therefore concluded that initial binding occurs at a de facto achiral site and not at a protein. Further corroboration for initial heme-docking came from the observation that the seemingly small modification $\mathbf{1 7} \rightarrow \mathbf{2 3}$, i.e. the epimerisation of artemisinin to epi-artemisinin, had a strong effect on biological activity. It dropped sharply. Modelling based on X-ray data clearly showed, that the inverted methyl group of the lactone ring of $\mathbf{2 3}$ shields the peroxidic bond, so preventing the molecule to dock efficiently on heme. ${ }^{12]}$ Another necessary condition a drug must meet in order to be highly potent is its capability to produce an aggressive, unhindered carbon-centred radical as the lethal agent. Compounds that break down via tertiary or neopentyl type radicals were only poorly active. This applies to $\mathbf{2 4}$ and many other compounds not shown here.

The development of an efficient and affordable synthetic antimalarial drug is an issue of global concern and extreme complexity. Worldwide research activity is going on in many laboratories, and Jefford's seminal work on 1,2,4-trioxanes and their mode of action fell in many instances on fertile ground. Nevertheless, there is not yet a single fully synthetic drug on the market. Most remedies rely on expensive semi-synthetic modifications of artemisinin itself or on hybrids with the old aminoquinoline motifs. One synthetic drug candidate, namely Hoffmann-La Roche's arteflene (29), a mimic of $\mathbf{1 8}$, was discontinued after phase III clinical trials and after nearly two decades of research investment (Fig. 3). Arterolane (OZ277) (30) developed by $J$. L. Vennerstrom at the University of Nebraska, USA is today's most promising fully synthetic drug candidate against malaria.[13] It is also a demonstration of the detours research can make. Ozonides $(1,2,4 \text {-trioxolanes })^{[14]}$ were used by chemists as synthetic intermediates for more than 100 years, i.e. ever since the introduction of ozonolysis by Harries in 1904 as an analytical and synthetic tool. Believed to be very unstable and sometimes even explosive, ozonides were overlooked and never properly tested for antimalarial activity. Ozonide 30 has now entered phase III clinical trials. Its central 1,2,4-trioxolane ring differs from the 1,2,4-trioxanes by just one carbon atom.

Parallel to his great activity in the field of antimalarials, Jefford had much interest in marine natural products their structure determination and their biological activity. In close collaboration with the Department of Marine Sciences of the University of the Ryukyus at Nishihara/Okinawa, Japan, and the Harbor Branch Foundation at Fort Pierce, Florida, he has published in that area more than a dozen of papers. Nearly all this work was done together with Gérald Bernardinelli, the remarkably prolific and gifted X-ray crystallographer at the University of Geneva.

In a department where the total synthesis of natural products played an important 


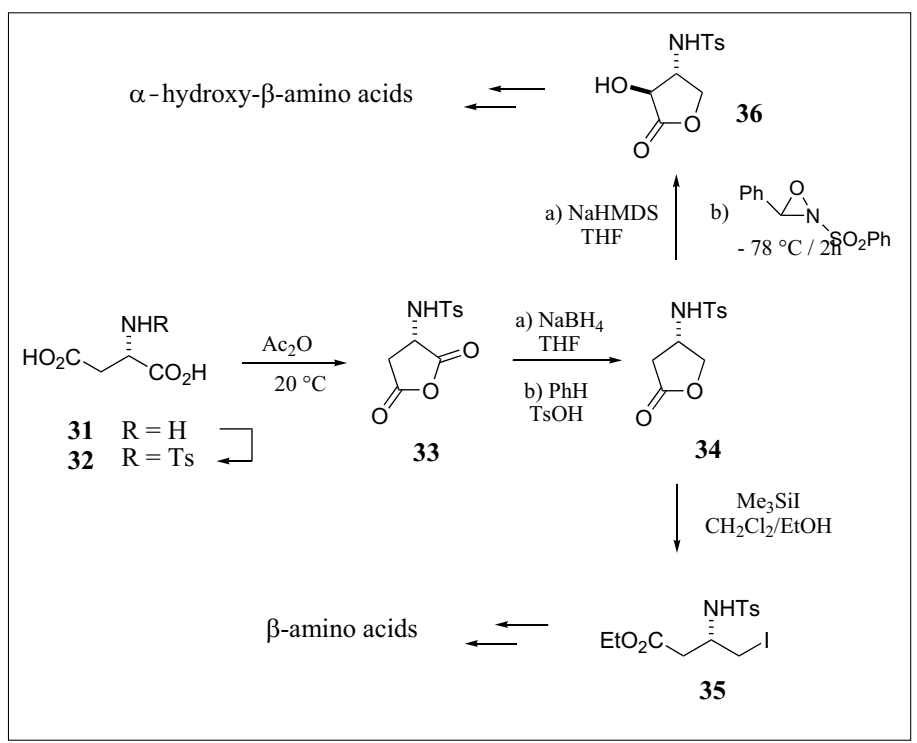

Scheme 6. Elegant template chemistry via butanolide 34 .

role, Jefford was not an outsider. Though synthesis per se was not his major issue, he has made many contributions to the field. ${ }^{[15]}$ Noteworthy is his template approach to $\beta$-amino acids and $\alpha$-hydroxy- $\beta$-amino acids which is outlined in Scheme 6.

Starting point was L-aspartic acid (31) which by tosylation (32), anhydride formation (33) and site-specific reduction with sodium borohydride gave the multipurpose (3S)-butanolide (34). Ring-opening with ethanolic $\mathrm{Me}_{3} \mathrm{SiI}$ gave the 3-amino-4-iodo ester (35) which, by coupling with an appropriate lithium dialkylcuprate, can be transformed into a large variety of $\beta$-amino acids. Alternatively, template $\mathbf{3 4}$ can be hydroxylated in stereospecific manner to 36, opened as above, and transformed into any desired $\alpha$-hydroxy- $\beta$-amino acid. ${ }^{[16]}$ This elegant template chemistry has found many applications.

Charles W. Jefford who celebrated this year his 80th birthday lives with his wife Susan in Bogis-Bossey, a village not far from Geneva. He is still a very active writer of scientific reviews and, more recently of short stories. The author of this eulogy, who had the privilege to know him for more than a quarter of a century as colleague, advisor and friend under the roof of Sciences II, wishes him all the best.

Received: October 14, 2009

[1] a) K. Fukui, in 'Topics in Current Chemistry', Vol. 5, 1, Springer-Verlag, Berlin, 1970; b) R. B. Woodward, R. Hoffmann, Angew. Chem. 1969, 81,797 ; c) M. J. S. Dewar, 'The Molecular Orbital Theory of Organic Chemistry', McGraw-Hill, 1969; d) H. E. Zimmerman, Angew. Chem. 1969, 81, 45.

[2] a) C. W. Jefford, D. T. Hill, Tetrahedron Lett. 1969, 24, 1957; b) C. W. Jefford, U. Burger, Chimia 1971, 25, 297.

[3] a) C. W. Jefford, T. W. Wallace, M. Acar, J. Org. Chem. 1977, 42, 1654; b) R. P. Johnson, A. Exarchou, C. W. Jefford, R. C. Hahn, J. Org. Chem. 1977, 42, 3758.

[4] a) C. W. Jefford, nT. N. Kabengele, J. Kovacs, U. Burger, Helv. Chim. Acta 1974, 57, 104; b) C. W. Jefford, J. Mareda, J. C. E. Gehret, nT. N. Kabengele, W. D. Graham, U. Burger, J. Am. Chem. Soc. 1976, 98, 2585.

[5] a) C. W. Jefford, A. F. Boschung, Tetrahedron Lett. 1976, 51, 4771; b) C. W. Jefford, A. F.
Boschung, Helv. Chim. Acta 1977, 60, 2673; c) C. W. Jefford, E. M. Jimenez, G. Barchietto, T. Berclaz, M. Geoffroy, Helv. Chim. Acta 1990, $73,1653$.

[6] C. W. Jefford, S. Kohmoto, J. Boukouvalas, U. Burger, J. Am. Chem. Soc. 1983, 105, 6498.

[7] a) C. W. Jefford, S. Kohmoto, D. Jaggi, G. Timári, J.-C. Rossier, M. Rudaz, O. Barbuzzi, D. Gérard, U. Burger, P. Kamalaprija, J. Mareda, G. Bernardinelli, I. Manzanares, C. J. Canfield, S. L. Fleck, B. L. Robinson, W. Peters, Helv. Chim. Acta 1995, 78, 647; b) C. W. Jefford, S. Jin, G. Bernardinelli, Helv. Chim. Acta 1997, 80, 2440.

[8] G. Schmid, W. Hofheinz, J. Am. Chem. Soc. 1983, 105, 624.

[9] D. L. Klayman, Science 1985, 228, 1049.

[10] a) C. W. Jefford, Adv. Drug. Res. 1997, 29, 271; b) C. W. Jefford, Curr. Med. Chem. 2001, 8,1803 ; c) C. W. Jefford, Curr. Opin. Investig. Drugs 2004, 5, 866; d) C. W. Jefford, Drug Discovery Today 2007, 12, 487.

[11] a) C. W. Jefford, J. A. Velarde, G. Bernardinelli, D. H. Bray, D. C. Warhurst, W. K. Milhous, Helv. Chim. Acta 1993, 76, 1775; b) C. W. Jefford, D. Misra, J. C. Rossier, P. Kamalaprija, U. Burger, J. Mareda, G. Bernardinelli, W. Peters, B. L. Robinson, W. K. Milhous, F. Zhang, D. K. Gosser Jr., S. R. Meshnick, in 'Perspectives in Medicinal Chemistry', Eds. B. Testa, E. Kyburz, W. Fuhrer, R. Giger. VHCABasel/VCH-Weinheim 1993, 459-472.

[12] C. W. Jefford, U. Burger, P. Millasson-Schmidt, G. Bernardinelli, B. L. Robinson, W. Peters, Helv. Chim. Acta 2000, 83, 1239.

[13] X. Wang, D. J. Creek, C. E. Schiaffo, Y. Dong, J. Chollet, C. Scheurer, S. Wittlin, S. A. Charman, P. H. Dussault, J. K. Wood, J. L. Vennerstrom, Bioorg. Med. Chem. Lett. 2009, 19, 4542.

[14] R. Criegee, Angew. Chem. 1975, 87, 765.

[15] a) C. W. Jefford, Pure Appl. Chem. 1996, 68,799 ; b) C. W. Jefford, J. McNulty, in 'Enantioselective Synthesis of $\beta$-AminoAcids', Ed. E. Juaristi, Wiley-VCH, Weinheim, 1997, p. 83-104.

[16] a) C. W. Jefford, Z. H. Lu, J. B. Wang, Pure Appl. Chem. 1994, 66, 2075; b) C. W. Jefford, J. McNulty, Z. H. Lu, J. Chem. Soc., Chem. Comm. 1995, 123; c) C. W. Jefford, J. McNulty, Z.H. Lu, J.B. Wang, Helv. Chim. Acta, 1996, 79, 1203. 